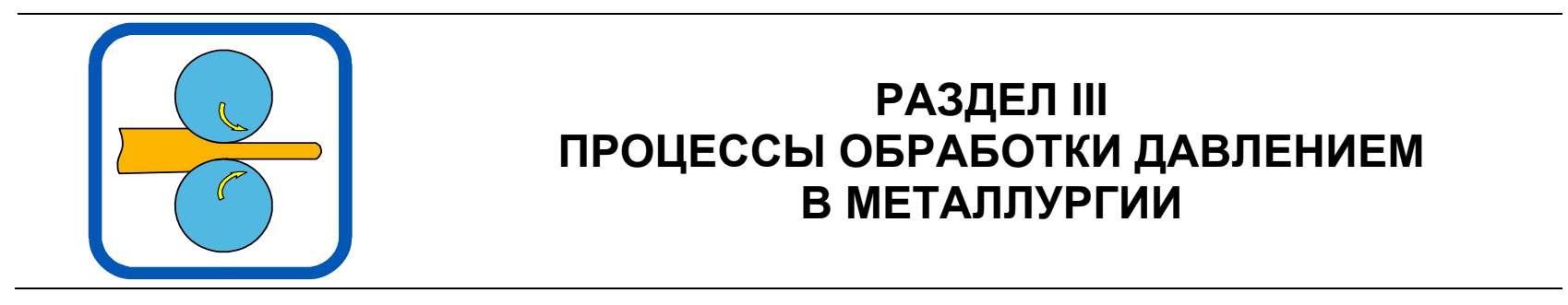

УДК 004.942; 621.771 .01

Грибков Э. П.

Бережная E. B.

Ивчик Р. С.

Коваленко А. К.

\title{
ИССЛЕДОВАНИЕ ВЛИЯНИЯ ДИСКРЕТИЗАЦИИ ОБЪЕМА НА ТОЧНОСТЬ РАСЧЕТА ПРОЦЕССА ПРАВКИ ЛИСТОВ МЕТОДОМ КОНЕЧНЫХ ЭЛЕМЕНТОВ
}

При конечно-элементном моделировании немаловажным фактором является дискретность разбиения объема деформируемого материала, которая влияет на точность и время расчета. С увеличением дискретности точность расчета увеличивается, но при этом резко возрастает время на его выполнение. Для определения минимально достаточного количества конечных элементов при сохранении точности по аналогии с работой [1] были выполнены исследования процесса правки листов на многороликовой правильной машине с изгибом рабочего ролика.

Листоправильные машины предназначены для исправления продольной кривизны листов, полученной во время прокатки [2-5]. Одним из путей совершенствования данного оборудования является создание изгиба оси рабочих роликов, что делает возможным дополнительное исправление поперечной кривизны листов [6]. При использовании данного типа машин актуальной является проблема определения оптимальной настройки рабочих роликов не только в продольном направлении движения листа, но и в поперечном, то есть определение помимо величины перекрытия роликов величину их изгиба. Указанное возможно при использовании трёхмерных математических моделей процесса правки листов [7-9]. Однако решение оптимизационных задач по определению технологических настроек правильной машины на основе трёхмерных конечно-элементных моделей занимает значительное машинное время, что делает актуальным определение рациональной дискретизации объема деформируемого металла с точки зрения минимизации времени расчета с допустимой точностью расчета.

Целью данной работы является определение рационального количества конечных элементов при трехмерном моделировании процесса правки листов с дефектом волнистости по критерию минимума затрат машинного времени при одновременном обеспечении достаточной точности расчета.

В рамках анализа напряженно-деформированного состояния металла при правке продольной и поперечной кривизны листов был выполнен расчет с использованием метода конечных элементов в системе Abaqus CAE.

Рассматриваемая применительно к анализу процесса правки листов на правильных машинах расчетная схема, которая представляла собой деформируемый лист и 6 рабочих роликов, представлена на рис. 1.

В соответствии с расчетной схемой (см. рис. 1) шаг машины $t$ был принят 275 мм, диаметр рабочих роликов равным 260 мм. Непосредственно моделирование процесса правки было выполнено для листа толщиной 10 мм. Для упрощения расчетов и ввода исходных 
данных материал считался не упрочняемым со свойствами упругости для стали $E=2,1 \cdot 105 \mathrm{H} / \mathrm{mм}^{2}, \mu=0,3, \sigma_{m}=400$ Па. Исходная конечно-элементная модель имеет следующие граничные условия: ролики имеют одну вращательную степень свободы. В расчете использовалась модель классической пластичности металла [10].

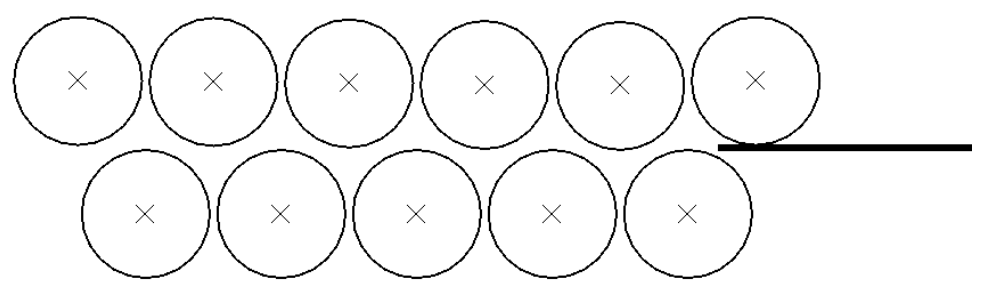

Рис. 1. Расчётная конечно-элементная в глобальной системе координат модель процесса правки листов на листоправильных машинах

Контакт между листом и роликами задавался при помощи модели контакта «Поверхность к поверхности» путем задания коэффициента трения $\mu=0,2$.

Рабочие ролики приводились во вращение с угловой скоростью 0,95 рад/сек. Скорость движения листа принята равной 1000 мм/с. Время шага было принято 2,5 с.

Для оценки полученных результатов выходными в данном случае параметрами были выбраны проекции реакций в контрольных точках роликов в глобальной системе координат $R F 2, R M 3$, а также перемещения, деформации и напряжения в узлах конечных элементов листа.

Для исследования процесса правки лист разбивали на различное количество ячеек, а именно: 300 (рис. 2, а); 1224 (рис. 2, б); 4545 (рис. 2, в); 7191 (рис. 2, г); 15014 (рис. 2, д).

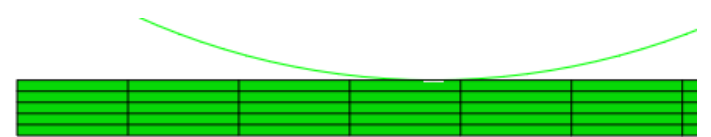

a

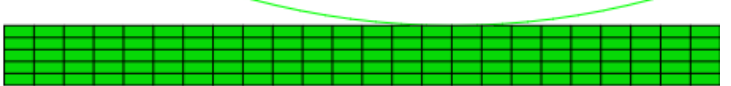

B

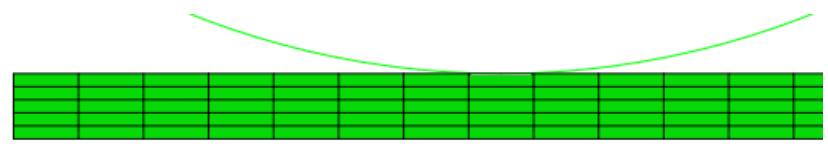

б

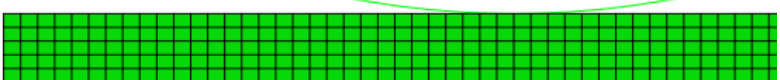

$\Gamma$

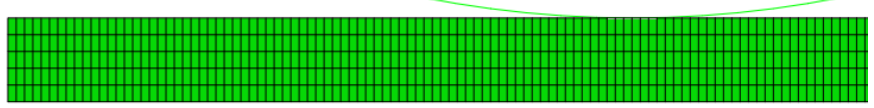

д

Рис. 2. Модели листов с различной дискретизацией объема:

a - 750; б - 1500; в - 3000; г-6000; д - 15000

В процессе расчета фиксировалось время расчета (рис. 3) и сила правки на третьем ролике (рис. 3). Было установлено, что с увеличением дискретизации объема деформируемого материала время расчета увеличивается практически линейно и при количестве ячеек 15120 составляет 4,2 часа (см. рис. 3). Полученные значения силы правки имеют значительный разброс, который уменьшается с увеличением количества элементов (рис. 4).

Используя полученный во время расчета ряд значений сил правки, был определен коэффициент вариации их разброса для каждого случая дискретизации объема, который составил более $15 \%$ в случае использования сетки из 750 элементов и порядка $1 \%$ при увеличении дискретизации более 6000 элементов (рис. 5), что позволяет сделать вывод о достаточности разбиения объема металла на уровне 6000 конечных элементов. Дальнейшее увеличение количества конечных элементов является нецелесообразным, так как приводит к значительному повышению времени расчета, более 11000 сек (см. рис. 3). 


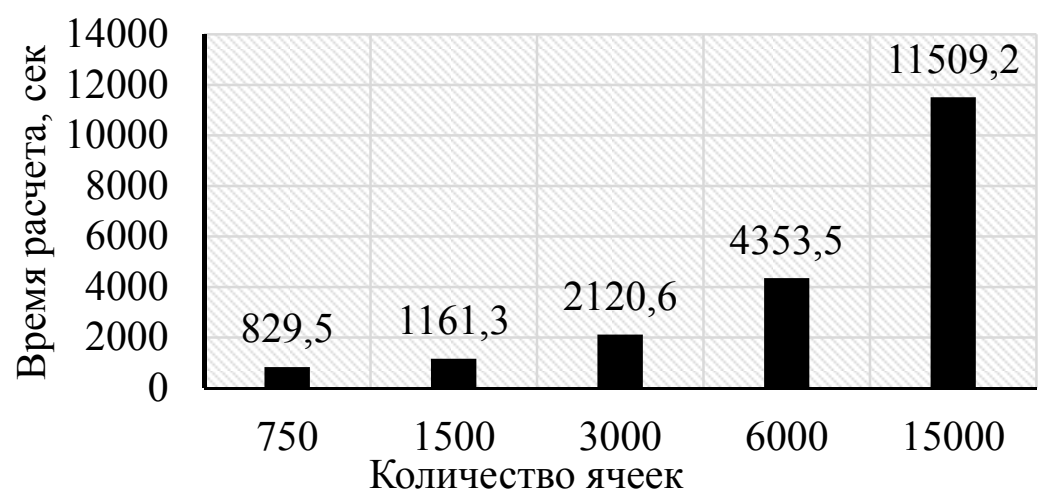

Рис. 3. Зависимость времени расчета от количества ячеек

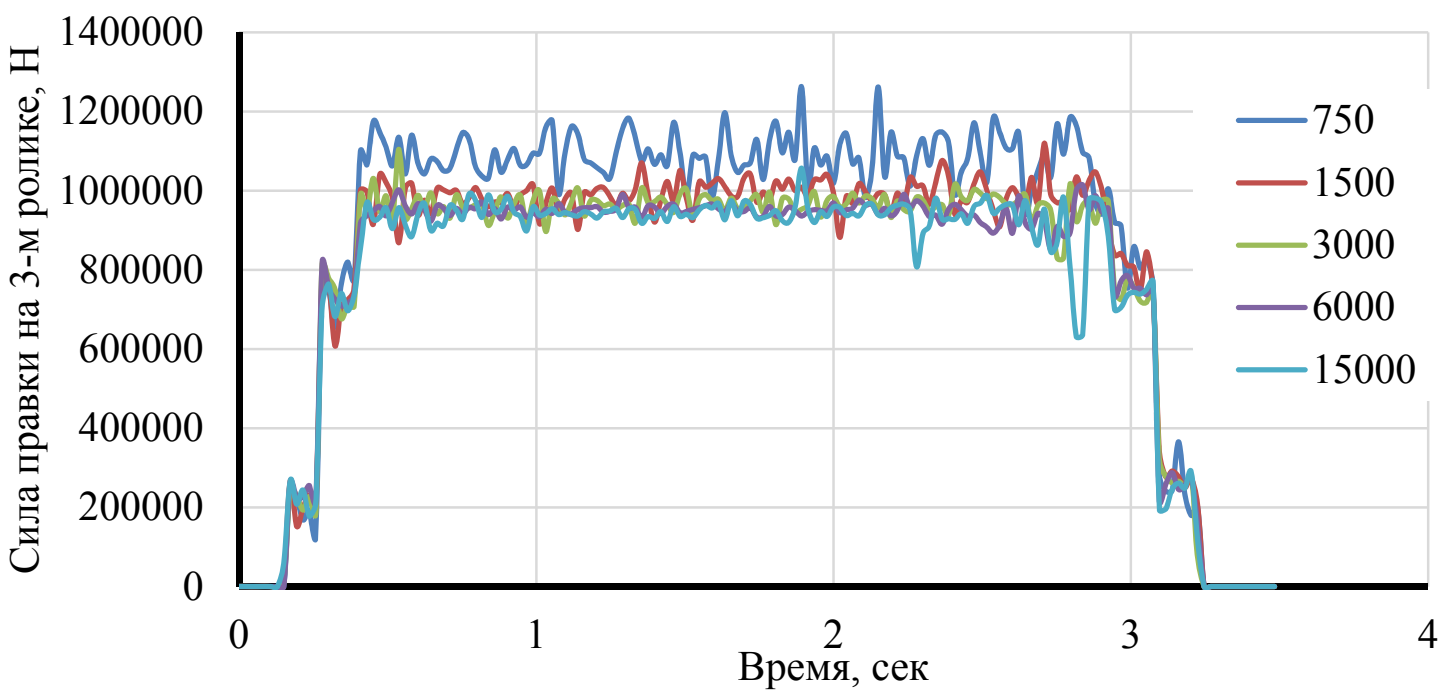

Рис. 4. Значения сил правки во время протекания процесса деформации в зависимости от количества ячеек

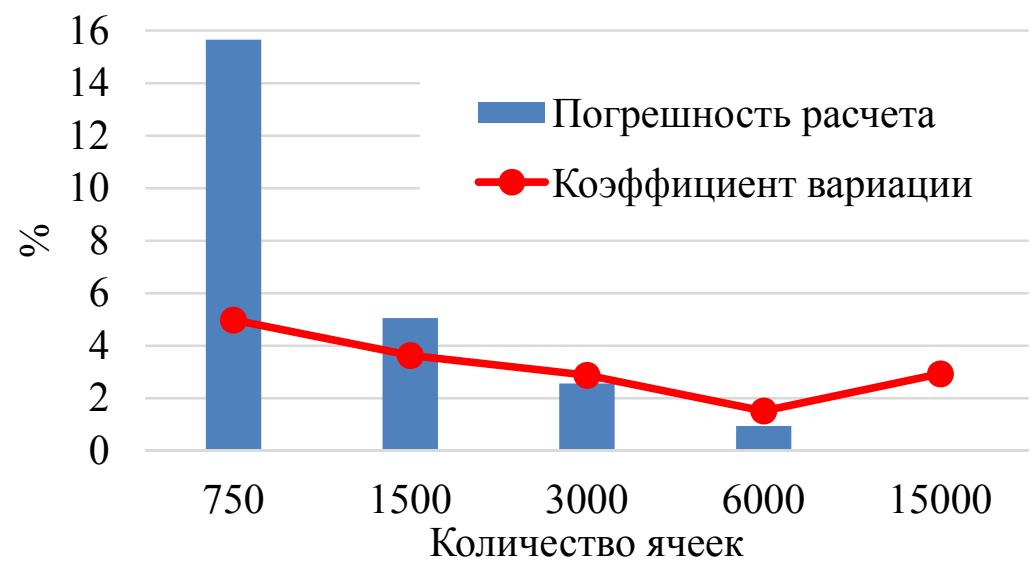

Рис. 5. Значения силы правки на третьем ролике и его коэффициента вариации в зависимости от количества ячеек

\section{ВЫВОДЫ}

В результате реализации конечно-элементной модели процесса правки листов было установлено, что при моделировании рациональным количеством является 6000 конечных элементов при расчете значения силы правки на третьем ролике. При этом время реализации модели составляет приблизительно 1,17 часа при значении коэффициента вариации силы правки на 1 \% выше относительно более точного значения. 


\section{СПИСОК ИСПОЛЬЗОВАННОЙ ЛИТЕРАТУРЫ}

1. Flatness defects after bridle rolls: a numerical analysis of leveling / N. Mathieu, R. Dimitriou, A. Parrico, M. Potier-Ferry, H. Zahrouni // International Journal of Material Forming. - 2013. - Vol. 6. - Issue 2. - Pp. $255-266$.

2. Слоним А. 3. Правка листового и сортового проката / А. З. Слоним, А. Л. Сонин. - М. : Металлургия, 1981. $-232 c$

3. Недорезов И. В. Роликовые правильные машины АО «Уралмаш» и пути их совершенствования/ И. В. Недорезов, Б. Я. Орлов, А. Х. Винокурский // Труды первого Конгресса прокатчиков. Магнитогорск, 23-27 октября, 1995. - М., 1996. - C. 38-42.

4. Королев А. А. Механическое оборудование прокатных и трубных цехов / А. А. Королев. - М. : Металлургия, 1987. $-480 \mathrm{c}$.

5. Луговской В. М. Теория расчета листоправильных машин и автоматизация их проектирования/ В. М. Луговской. - Труды ВНИИМЕТМАШ. - М. : Металлургия, 1970. - № 26 - С. 8-30.

6. Шинкин В. Н. Расчет технологических параметров правки стального листа на одиннадиатироликовой листоправильной машине линии поперечной резки фирмы Fagor Arrasate / В. Н. Шинкин // Производство проката. - 2014. - № 8. - C. 26-34.

7. Park K. Development of a Finite Element Analysis Program for Roller Leveling and Application for Removing Blanking Bow Defects of Thin Steel Sheet / K. Park, S. Hwang // ISIJ International. - Vol. 42 (2002), No. 9. Pp. 990-999. - http://dx.doi.org/10.2355/isijinternational.42.990.

8. Cui L. Analysis of Leveling Strategy for a plate Mill / L. Cui, X Hu, X. Liu // Advanced Materials Research. Vol. 145 (2011). - Pp. 424-428. - http://doi:10.4028/www.scientific.net/AMR.145.424.

9. Cui L. Research on Mathematical Model of Leveling Process for Plate Mill / L Cui, X. Hu, X. Liu // Advanced Materials Research. - Vols. 148-149 (2011). - Pp. 368-371. - http://doi:10.4028/www.scientific.net/AMR.148-149.368.

10. Кроха В. А. Кривые упрочнения металлов при холодной деформации / В. А. Кроха. - М. : Машиностроение, 1968. - $131 \mathrm{c}$.

\section{REFERENCES}

1. Flatness defects after bridle rolls: a numerical analysis of leveling / N. Mathieu, R. Dimitriou, A. Parrico, M. Potier-Ferry, H. Zahrouni // International Journal of Material Forming. - 2013. - Vol. 6. - Issue 2. - Pp. $255-266$.

2. Slonim A. Z. Pravka listovogo i sortovogo prokata / A. Z. Slonim, A. L. Sonin. - M. : Metallurgija, 1981. - 232 s.

3. Nedorezov I. V. Rolikovye pravil'nye mashiny AO «Uralmash» i puti ih sovershenstvovanija / I. V. Nedorezov, B. Ja. Orlov, A. H. Vinokurskij // Trudy pervogo Kongressa prokatchikov. Magnitogorsk, 23-27 oktjabrja, 1995. - M., 1996. - S. 38-42.

4. Korolev A. A. Mehanicheskoe oborudovanie prokatnyh i trubnyh cehov / A. A. Korolev. - M. : Metal-lurgija, 1987. $-480 \mathrm{~s}$.

5. Lugovskoj V. M. Teorija rascheta listopravil'nyh mashin i avtomatizacija ih proektirovanija / V. M. Lugovskoj. Trudy VNIIMETMASh. - M. : Metallurgija, 1970. - № 26-S. 8-30.

6. Shinkin V. N. Raschet tehnologicheskih parametrov pravki stal'nogo lista na odinnadcatiroliko-voj listopravil'noj mashine linii poperechnoj rezki firmy Fagor Arrasate / V. N. Shinkin // Proizvodstvo prokata. - 2014. - № 8. - S. 26-34.

7. Park K. Development of a Finite Element Analysis Program for Roller Leveling and Application for Removing Blanking Bow Defects of Thin Steel Sheet / K. Park, S. Hwang // ISIJ International. - Vol. 42 (2002), No. 9. Pp. 990-999. - http://dx.doi.org/10.2355/isijinternational.42.990.

8. Cui L. Analysis of Leveling Strategy for a plate Mill / L. Cui, X Hu, X. Liu // Advanced Materials Research. Vol. 145 (2011). - Pp. 424-428. - http://doi:10.4028/www.scientific.net/AMR.145.424.

9. Cui L. Research on Mathematical Model of Leveling Process for Plate Mill / L Cui, X. Hu, X. Liu // Advanced Materials Research. - Vols. $148-149$ (2011). - Pp. 368-371. - http://doi:10.4028/www.scientific.net/AMR.148-149.368.

10. Kroha V. A. Krivye uprochnenija metallov pri holodnoj deformacii / V. A. Kroha. - M. : Mashino-stroenie, 1968. $-131 \mathrm{~s}$.

Грибков Э. П. - - д-р техн. наук, доц. кафедры АММ ДГМА;

Бережная Е. В. - - д-р техн. наук, доц. кафедры ПТМ ДГМА;

Ивчик Р. С. $\quad$ - вед. констр. ЧАО «НКМЗ»;

Коваленко А. К. - ассистент кафедры КИТ ДГМА.

ДГМА - Донбасская государственная машиностроительная академия, г. Краматорск.

ЧАО «НКМЗ» - Частное акционерное общество «Новокраматорский машиностроительный завод», г. Краматорск.

E-mail: $\underline{\text { amm@dgma.donetsk.ua }}$ 